\title{
Cave dwellings in the Mediterranean Basin
}

\author{
Urdiales Viedma María EugeniaA*, Maccarone Alessandra ${ }^{B}$ \\ Received: July 2011 | Revised: October 2011 | Accepted: November 2011
}

\begin{abstract}
The construction and use of subterranean caves for different functions has been relatively commonplace throughout history in different regions around the world, especially in the Mediterranean basin. Some of them are still standing at the beginning of the 21st century, and are a good example of adaptation to the geographic environment, and a part of the historical heritage.

Following a short overview of the different Mediterranean countries, this work pays special attention to the present use of caves as dwelling spaces in Italy, and particularly in Spain where the caves are currently in an interesting process of renovation to meet the needs of the present population. This process is helping to boost the local economy, and it is funded by both private and public sources in several towns in Andalusia [Spain].
\end{abstract}

Keywords: Cave dwelling, Mediterranean basin, popular house, cultural heritage, bioclimatic housing

\section{Introduction}

The excavation of subterranean areas has been relatively common throughout Human History, having developed a wide range of functions, chief among them mining, water transportation, product and tool storage, and as places of worship, cemeteries, and more frequently as human dwellings, making the excavated home a typical popular construction and a relevant element within the rural landscape which reflects the cultural heritage of its dwellers. Multiple variables converge into its genesis and maintenance, among which environment, lifestyle and economical activity are of particular importance.

The extent of these dwellings has been notable across several geographic areas. The Mediterranean basin is one of these privileged regions; its coastal countries still retain some of these original constructions, which contrast with the homogeneity of conventional housing construction which is the product of standardized building methods in our current civilization. The positive valuation of these constructions produced rescue efforts to salvage these dwellings as cultural heritage, while encouraging their practical utilization in order to foster the development of rural areas at the beginning of the 2Ist century.

In the present work we present a synthesis of a number of previous studies on the cave dwellings, alongside a new study carried out by the authors about the present and prospective status of these homes.

\section{The Cave Dwelling as Popular Housing}

Throughout history, populations have continuously adapted to their environments, developing their own "façon de vivre" (Derruau, I983). From a variety of options offered by the environment, individuals have made choices to satisfy their own needs. The specificities of each territory, the established priorities, and the different technological levels of each society also imply different results in each geographic area. The amplitude of the concept (façon de vivre) ranges from the structure of economic activity to the establishment of specific cultural patterns, along with the methods of house construction and the setting of population centers.

\footnotetext{
A Department of Human Geography, Faculty of Letters and Philosophy; University of Granada, Spain

B S.A.V.A. Department, Faculty of Engineering, University of Molise, Campobasso Italy

* Corresponding author: Urdiales Viedma María Eugenia, e-mail: urdiales@ugr.es;

co-author: Maccarone Alessandra, e-mail: alessandra.maccarone@unimol.it
} 
The current process of universality in house construction typologies began with the Industrial Revolution, although this phenomenon experienced a more significant development during the zoth century, especially in its second half when urbanization was intensified. In contrast with this tendency (mostly urban), the popular house continues to exist especially in rural environments, where it continues to have a substantial presence while it helps to characterize the rural landscape.

Within this general frame work, the cave dwelling has developed a rather significant role in that it reflects the conditions of the natural environment, and at the same time it has been configured as an example of a construction that adapts to the needs and priorities of the population that inhabit these dwellings. As with other kinds of popular houses, caves have a set of specific characteristics that permit an individualized analysis. First of all, it must be born in mind that it is a construction that has not been conceived nor designed by architecture professionals, but rather it is the result of intuitive knowledge, forged over time by the populations of different cultures. As a consequence, its execution has been frequently carried out by its own dwellers, with the help of family or neighbors.

\section{Part of the Cultural Heritage}

The popular house represents the values and traditions of the community in which it has developed, and which are also part of the whole process in both conception and development. These are constructions built in accordance with the uses and the needs of their dwellers. That implies that the house need not be conceived in a definitive manner, but that it progressively adapts to new requirements of the familiar and economic entity it serves. This subordination is shown in the adaptation of the construction to changes in the size of the family, economical specialization, or any other change that takes place in the familiar system of production.

Originality is another of its differentiating features, which implies significant constructive differences between some places and others, far from the morphologic homogeneity that conventional houses have in the current framework of globalization due to the expansion of the western way of life. Its specific features and valuation as part of the cultural heritage have caused popular houses to be deemed an interesting territorial resource in the process of economic diversification and fostering the rural environment.

\section{Functional Diversity}

Traditionally, rural housing has had the double function of providing shelter to its dwellers, and being an essential complement for the development of economic activity, mainly agrarian. The peculiar natural environment, the kind of peopling (disperse or concentrated), the complexity of agrarian landscapes, and the different types of property and exploitation, lead to a remarkable diversity in popular housing.

With the passing of time, its traditional economic function has declined (as has agrarian activity), thus popular housing is increasingly being identified with its residential function and can be readapted as well to the current socioeconomic conjuncture of the rural environment, mainly through the development of other economic activities, usually related to the hostelry industry.

\section{Adaptation to the Geographic Environment}

When excavating the caves, the population has applied simple and intelligent techniques to take advantage of favorable conditions that the environment offered. Amongst these, geomorphic and climatic peculiarities of the territory are to be highlighted (Urdiales, 1987).

In fact, the selection of adequate materials is a key issue. The preferred terrains are composed of volcanic or sedimentary materials that are easy to excavate and have the capacity of becoming harder as time goes by. Sandstone, clay, marlstone or tertiary conglomerates with solid foundations fulfill the basic conditions required for a cave dwelling, not only for the ease of the excavation process but also for the subsequent safety of the interior.

Complementarily, certain climatic conditions are required, among which low precipitations and continental climate features deserve to be highlighted. In those conditions, caves perform adequately thanks to the isotherm they generate (around $\mathrm{I} 4 / \mathrm{I} 9^{\circ} \mathrm{C}$ ), which creates a microclimate in contrast with the more extreme values typical of continental climates. However, climatically speaking, there are some disadvantages. A major one among these is the "torrential" nature of rains common in this type of climate, and its capacity to erode these materials which are fundamentally soft and frequently lack vegetation. This significant disadvantage is counteracted with masonry works that can always be found in current excavated housing.

Another disadvantage is related to the slow, yet continuous, erosion of the materials caused by sharp temperature changes, and the penetration of water into small fractures in the rock, causing its volume to increase when water solidifies into ice. The greater or lesser effect of this variable is closely dependent upon the temporal extension of sub-zero temperatures, which frequently last longer than six months in continental climates. 
In addition to the aforementioned geological variables, we should point out the poverty which to a greater or lesser extent has affected the population segments in several geographic environments, and has fueled the development of caves in contemporary history, especially due to the necessity of rapidly constructing inexpensive housing.

\section{Extension and Range of Cave Constructions}

Traditionally, caves were deemed to be primitive constructions commonly used as shelter, sanctuary, cemetery and complement to agrarian activity or house. Each of these functional versions of caves has spread through the continents,

As caves extended eastward away from the Mediterranean, into the clay earth of the plateaus in Iran, Iraq and India, and as far as the loessic materials of Northern China where they are still in use. The Ellora Caves (India), which contain several Buddhist, Hindu and Jain Temples excavated inside basalt cliffs, are especially famous and have been declared a UNESCO World Heritage Site. This type of constructions can also be found in the recent past of the American Continent, from North America to Tierra de Fuego (Urdiales, 1987), which is yet another example of adaptation to the peculiar geographic conditions of each region.

Among the different geographic areas with excavated constructions, the Mediterranean basin (Jessen, 1955) might have been -and continues to be- the most representative, owing to the presence of caves in several coastal countries such as Italy, Greece, Tunisia, Libya, Turkey, France and Spain, amidst which we can cite the settlements of Puglia, Molise and Basilicata (Italy), Petra (Jordan), Matmatah (Tunisia) and Andalusia (Spain), just to mention the better known ones.
With the passing of the time, the number of constructions has significantly declined, at the same time that its original structure has been modified for the purpose of adapting it to the new requirements imposed on it by the population, regardless of whether they were consecrated to traditional uses or to more recent and innovative ones. This interesting process of renovation has found particular expression in the region of Guadix (Andalusia, Spain) where this type of dwelling is very much appreciated by the population. Currently Guadix is the city in Spain with the greatest number of persons living in caves.

\section{Jordan}

The presence of subterranean constructions in Jordan recalls the ancient city of Petra, excavated in Paleozoic sandstone and which became the capital of the Nabateans in the 6th century B.C. Its economic and political relevance lasted until the 8th century, when Petra was abandoned. Little attention was paid to the neglected city, until it was discovered by Swiss explorer Johann Ludwig Burckhardt in I812 (Maccarone, 2009). thereafter it progressively became one of the most important tourist destinations in the world, bringing about the interesting rehabilitation and construction of new subterranean chambers to serve A growing touristic demand. In I985 this effort was rewarded with UNESCO recognition as a world heritage site, and with the creation of the National Archaeological Park of Petra in 1997 (Figure I).

\section{Turkey}

Turkey is one of the countries that best represent the excavated architecture that extends from the Cappadocia region to a prairie at approximately $\mathrm{I} .000 \mathrm{~m}$ of altitude in the Nevşehir province.

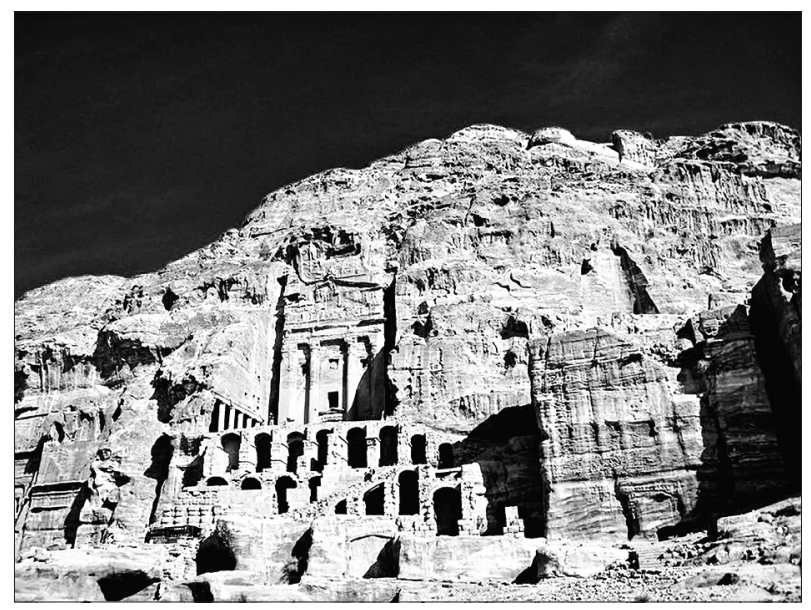

Figure 1. Petra: the lost city, UNESCO World Heritage, 1985

Photo: www.pixmac.es

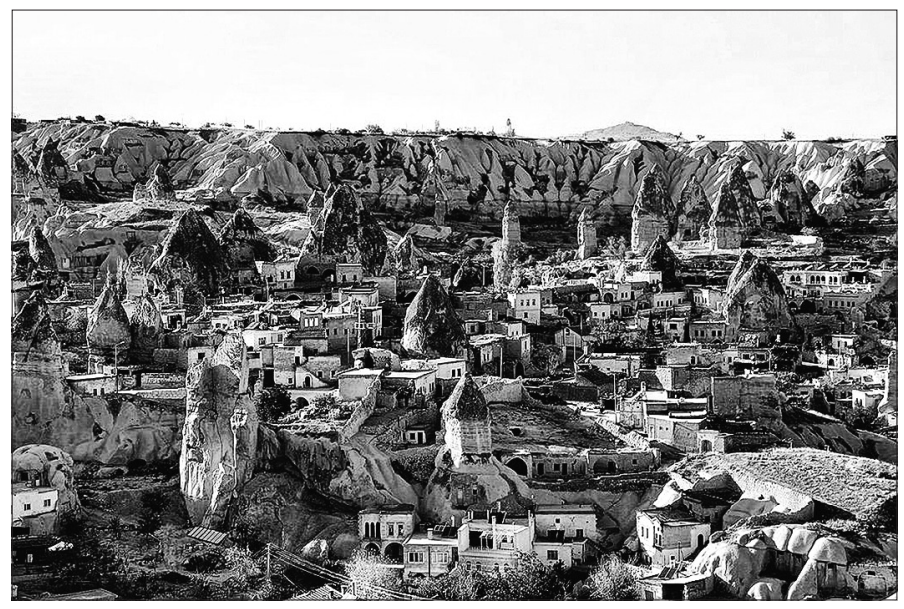

Figure 2. Pierced housing in "Fairy chimneys" in the Göreme valley, Cappadocia

Photo: wikipedia.org/wiki/Benutzer:Grizurgbg 
The terrain that has been excavated is essentially $y$ tuff, which has been drilled throughout History and has resulted in a fabulous landscape of towers, crevices, pinnacles and castles, known as fairy chimneys (Figure 2). They were initially used as a refuge by anchorites, although during the Byzantine period the caves became increasingly used for housing purposes, which use continues today and has given birth to subterranean cities with several levels of habitability, communal kitchens, wells, drains and cisterns (Maccarone, 2009). This cultural resource has been utilized to drive tourism development in the area, particularly in the townships of Göreme, Kaymakly and Deinkuyun, especially after the AREA was declared a UNESCO World Heritage Site in I985 and Latera National Park was created.

\section{Tunisia}

The caves in Tunisia are located in the South, in the sub-desertic area between Medenine and Tataoune, but mostly they have spread around the great mountain arc of Jbel, which ranges from Matmatah to Tripoli. Its origins in the VIII century were defensive and the excavation of marlstone and limestone has been carried out since then by the Berber population (Maccarone, 2009). Its use continued over time, although after the Independence of Tunisia (1957), a land reapportionment policy was implemented with a view to reactivating the South of the country; This resulted in the abandonment of a great number of the caves due to the transfer of their dwellers to house constructions, especially in the Douiret township (Figure 3).

These caves can be divided into two types: houses that were horizontally excavated into hillsides, and those that were built vertically. The latter are the most common in Matmatah, where we can find an extraordinary subterranean housing complex, frequently with two levels, one for hous-

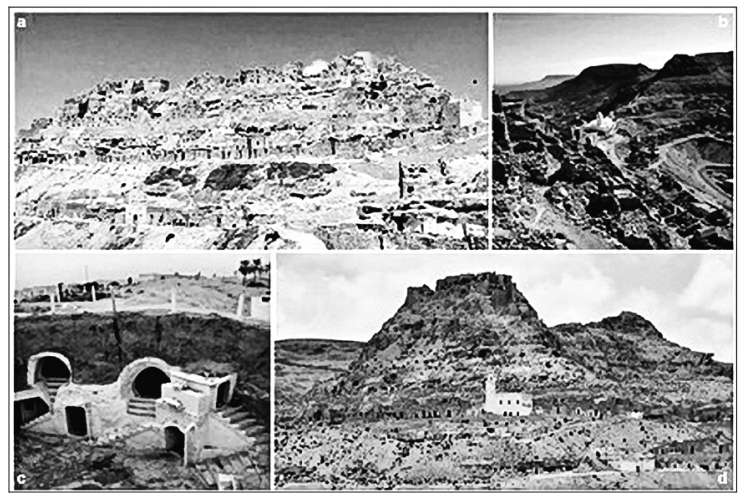

Figure 3. Tunisian Bereber settlements: Chenini $[a, b]$; Matmatah [c] e Douiret [d]

Photo: A. Maccarone, 2009 ing and another for storage. This site enjoys international fame for the filming of Star Wars, which in turn has fostered tourism in the region, an activity that takes advantage of the adaptation of subterranean constructions for retail and hostelry activities. Complementarily, the constructions are still used for housing purposes.

\section{Italy}

This country's central position in the Mediterranean basin has favored the establishment of several peoples on its territory, to which they brought their culture and way of life. As with the aforementioned countries, the excavation and the use of subterranean spaces has been quite frequent, especially in the southern half of the country and its islands. In fact, traces of this important historical and cultural heritage have been found in Sardinia (Alghero) and Sicily (Pantalica), where they served for defensive, funerary, religious or housing purposes. After the XIV century some of these traditional functions were abandoned, but they were kept mainly for defensive purposes (Maccarone, 2009).

In the peninsula, subterranean constructions have spread through the regions of Calabria, Molise, Puglia and, specially, Basilicata. In Puglia, excavated houses and sanctuaries have expanded over the Taranto province, where an urban structure with several levels on top of the others has been excavated into sand-lime. The region of Molise features a relevant heritage of subterranean sites that have served several purposes throughout History, among which defensive, religious, water piping, funerary, storing and residential are to be highlighted. The state of neglect these caves have endured until very recently has been the reason for the scarce use of these constructions, and for the lack of interest in them by authorities and researchers. However, in the past few years there has been a new and growing interest in these structures which has triggered further research on this geographic topic with a view to strengthening said heritage, as is also happening in other areas of the Mediterranean basin (Maccarone, 2009).

Near these areas, in Basilicata, is Matera, the most relevant area in Italy. Declared part of UNESCO World Heritage in I993, it is an example of a way of life in harmony with the environment. Its urban structure is laid out in the shape of a "W" with three arms, the central of which, called Civitas, constitutes the earliest core, pierced and inhabited since the Mid Paleolithic and for a long time thereafter, all through the successive settlements of a number of civilizations: Greeks, Romans, Lombards, Normans, Arabs, Byzantines. Over time, the lateral flanks of the massif were also occupied. 
The soil into which the settlement was dug is composed of limestone and sandstorm, which are soft, compressible, easily removed materials. This substratum, along with the particular orography of the region and also the presence in the valley of very fertile plains, created the ideal conditions for a hypogean city instead of a constructed one.

The caves are located throughout the mountainsides, being therefore distributed on superimposed levels. There is also a network of stairs connecting caves with each other. The cave's inner structure is quite simple, usually consisting of only one room where people and animals used to live together (Figure 4). A common external space lays/stretches in front of the cave like a square, which constitutes an architectonic feature typical of this sort of settlement. The above-mentioned feature is also noticeable in Spanish caves.

The expansion of the conventional (non-excavated) urban core began in the $17^{\text {th }}$ century as -when the city became the capital of Basilicatanew dwellings and public buildings were erected at the foot of the original excavated enclave. The standard of living starts to improve, and in that context the caves could no longer come up to a sanitary and comfort standard. Nevertheless they continued to be inhabited, as Carlo Levi highlighted in his description of the region (I945), a text of the utmost importance from which we can deduced the living conditions of the inhabitants of Matera's caves in the early-mid $20^{\text {th }}$ century. At that point it was estimated that 3,329 excavated houses spread out across a surface OF 300,000 meters square: "inside those black holes, along the earthy walls the beds, the very poor hand tools, the cloths. There are dogs, sheep, goats and pigs lying on the floor. Each family has got, in general, a single cave for shelter where they all live together, men, women, children and animals. So live 20,000 people. There was a multitude of children. In that heat, amid the flies and the dust they showed up from everywhere necked or covered with rugs. I've never seen a picture of misery like that". Matera was regarded as "the shame of Italy" as a consequence of the tremendous social and political impact of the media outcry surrounding it. The population was forced to abandon the caves, which became state property and were immured in order to prevent them from being reoccupied (Maccarone, 2009). Thus "the Sassi from Matera turned into a dead city, the biggest historical deserted centre in Europe".

The deteriorating landscape which resulted from the collapse of houses and churches, sparked a grassroots movement that in 1986 pressured the government into passing a bill (271/1986) developed by the local administration, which allowed the restoration of the enclave caves, focusing mainly on sanitation and urbanization. In

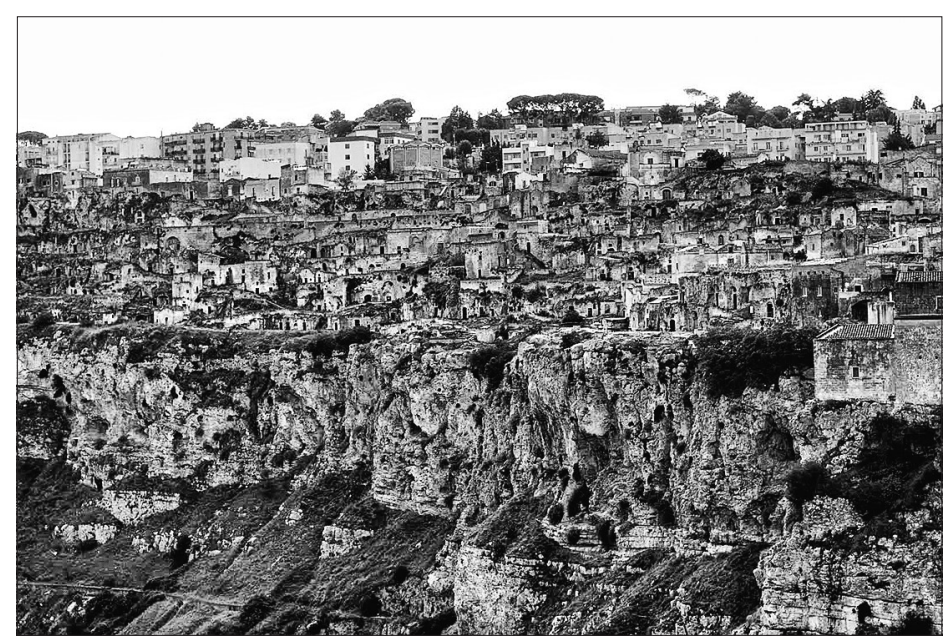

Figure 4. Matera, considered as the first centre of southern Italy in the list of UNESCO World Heritage Source: australiatoitaly.blogspot.com

addition, a wide incentive campaign was developed to lure back the population. This decisive public action (coupled with the recognition of the site by UNESCO) has led to the revaluation of these properties; It has also marked the beginning of a new era of municipal splendor, to the point that in 2007 over 4,000 people were living in the caves. Moreover, several restoration projects that would double the population of the excavated site (Laureano, 2007) were set in motion. The recovery tasks have also included over a hundred fairly well-preserved shrines, and a wealth of interesting frescos similar to those of Cappadocia. Thus, the Sassi have become the most important experience in recovering subterranean architecture in the Mediterranean basin.

\section{Spain}

The caves were used from the beginning of History, when people utilized natural holes in rocks. In Spain there is no continuation from early times. In fact, the use of caves as dwelling places had its origins in recent centuries, especially from $\mathrm{I} 8 \mathrm{oo}$ to I950, coinciding with an important demographic increase accompanied by immigration to and cultivation of the new lands which followed the "desamortization" measures of Mendizábal (1836) and Madoz (1855). Those factors were very significative in the province of Granada, especially in the region of Guadix, Baza and Huéscar, where the number of caves was rapidly increasing due to low prices (Urdiales, I987).

The new inhabitants in this area arrived from eastern Spain, especially from the provinces of Murcia, Albacete, Alicante and Valencia, where this type of dwelling was commonplace. During the first half of the XX century demographic growth and the increasing number of inhabited caves made 


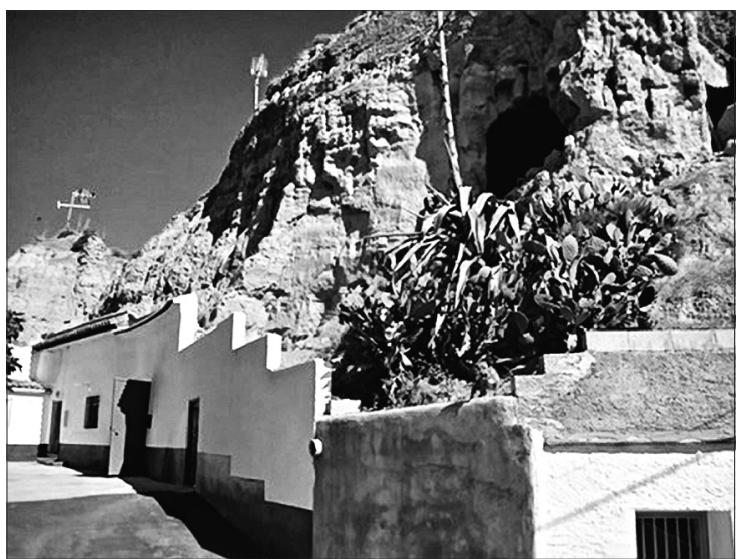

Figure 5. Hill with caves in Purullena, Granada. Photo: A. Maccarone, 2009

Spain the Mediterranean country with the largest population of cave dwellers (Jessen, I955). Even in the years that followed, use of the caves extended to the greater part of Spain except in the north and west. In recent decades the number of caves has decreased. At the start of the XXI century there remain only a few inhabited caves in some regions: Aragon, Pais Valenciano, Murcia, Castilla la Mancha and Canarias, with Andalusia leading as the region with the greatest number of cave dwellings in Spain $50 \%$ of all caves in of all caves in the country in the I960s). since that time, the significance of cave dwellings has waned, and since the end of the last century distribution of the caves has been very unequal across the various provinces (Lassaosa, I987): Grenade (82\%), Jaen (8\%), Cadiz (3\%), Seville ( $\mathrm{I}, 4 \%$ ) and Cordoba (o, $6 \%)$.

According to these figures, the province of Granada is a privileged area for the study of cave dwelling, from a historical point of view as well as for their important presence, and last but not least for the transformation that the caves are undergoing. The use of caves as dwellings is being transformed from a primitive way of life, an infra-dwelling, to a bioclimatic home with major growth potential in a scenario of "relaunching" rural spaces (Urdiales, 2003). The caves, are concurrently undergoing improvements as dwelling places and being put to new uses as emergent rural-tourism lodgings (Figure 5).

\section{The Abandonment of Caves, the Re- appreciation of Residential Use and Development of Alternative Options on the Threshold of the $21^{\text {St }}$ Century}

The abandonment of inhabited caves continues all across Andalusia, including the province of Granada, although in areas with large numbers of caves some houses have been constructed on preexisting holes at their original sites. A thorough study of this phenomenon in a wider geographi- cal region is nearly impossible because census records make no mention of partial excavations; in cases where a house was classified as an accommodation, it would not appear on the census because it is often used as a second home, not the primary dwelling. Therefore, the information recorded on the previous census is not exact and obscures the actual number of inhabited caves.

In recent years, use of the caves encouraged along with traditional residential use within the framework of programs for development, economic diversification and tourism promotion of rural areas. As for the morphological and functional structure, this enclave is assembled in a small hotel complex furnished with all the amenities that demanding customers would require. Some of them even have meeting facilities designed to satisfy a wide range of demands from potential visitors.

The accelerated pace of this rehabilitation project is due to the positive public response to the caves, and the concurrent boost of equally supportive public policies.

\section{Support Policies}

Some years after the autonomous government of Andalusia was granted by the central government the legislative power over housing in I984, a new era in housing policies began which was made evident by the increased interest in the Andalusian phenomenon of caves and their display by regional authorities. Such an interest was likewise reflected in the publication of specific works on the subject (Urdiales, 1987 and Lasaosa, 1989) and in Housing Planning guidelines that since 1992 address the issue of slum dwellings.

In adherence to these plans, local governments are expected to work toward the improvement of the most poorly furnished and ill-equipped homes, which in Andalusia corresponded precisely to the inhabited caves. Thus, for example, the Plan currently in force issues the guidelines on how to obtain public assistance through the intermediary action of municipalities for renovation projects, building new floors, and development, placing special emphasis on safety, lighting, ventilation and sanitation. (Concerted Plan for Housing and Land 2008-20I2, art. 74, published for the regional government of Andalusia -Boja $\mathrm{N}^{\circ} 235$ - in November $26^{\text {th }}, 2008$ ). This plan is aimed at low-income persons. Although it is impossible to quantify the exact number of caves that have been restored, it is evident that in the past 15 years there has been an impressive leap in the recovery and marketing of these homes, as a result of both decisive official support policies and favorable public opinion on the matter. 
Thus, private investment has now joined official subsidies for local residents with fewer financial resources, in the completion of dwelling renovation projects. In regard to this, it is noteworthy that the situation in Bácor-Olivar, in the municipality of Guadix where caves are still the most widespread type of housing (about $75 \%$ of the total number of homes), although they have been granted hardly any official subsidies because these caves are being occupied by persons with incomes above the threshold set by the regional government of Andalusia. The specific case of this population core is extreme, both for the significance of cave dwellings and their extensive use in this region, as for the importance of privately-funded restoration projects. Nonetheless, the refurbishment of the caves, undertaken by the owners themselves, is also common to other municipalities with caves, which is a clear indication of the value the population attaches to the caves, undoubtedly considered as part of their architectural and residential heritage.

Another action that complements the regional government of Andalusia's policy regarding cave rehabilitation, is that of The Council for Tourism, Trade and sports, which offers grants aimed at modernizing and developing tourism within the framework of modern and sustainable development. In this regard, political action is specifically directed at the rehabilitation of caves for rural tourism, understood as one of the Andalusian region's development potentials. This new purpose for the caves has been seized on since the nineties, and in the past few years has witnessed explosive growth. Initially, the rehabilitation of the caves for tourism was largely staged by foreign developers, which over time have been joined by increasing numbers of local investors armed with funds from private sources. additionally, public administrations have also helped with partial subsidies for construction projects.

In addition to the issue of slum dwellings, another concern yet to be addressed is the lack of proper sanitation and of road networks in these slums.

To tackle this task, the provincial government has been entrusted with drafting general guidelines for the creation of concrete plans to improve urban planning and land management in cave site areas. These guidelines are intended to create a consensus on basic criteria to be considered by each municipality when drafting sanitation and land management plans. Those rules were outlined in the document drafted by the council in the context of the European Project (Eurocuevas) proposed and encouraged by the Council of Granada; The project included 26 municipalities in the province, along with other regions in five Eu- ropean countries. The document is interesting in two respects: not only does it provide guidance to local authorities, it is also an attempt to coordinate projects with other countries in the Mediterranean basin where similar dwellings are found and that wish to support them as a constituent part of their landscape and heritage.

With this objective, the project is divided into 5 clusters: legal matters, construction, urban planning, economic development and cultural heritage. For each one of these areas of work a set of guidelines has been drafted, with recommendations stating how resource management should be exercised. (Council of Grenade, 2007). To sum up, even though the phenomenon of caves dwelling is widespread throughout Andalusia; although relevant legislation has been developed, specific laws regulating that heritage are still needed because the originality and peculiarities of that heritage do not lend themselves to the implementation of conventional housing and urban planning regulations.

\section{Conclusions}

The excavation and adaptation of the underground habitat in the Mediterranean basin have been carried out by various peoples throughout history. concrete proof of this is the number of regions with caves dwellings which are located on both shores of the Mediterranean Sea. This type of dwelling belongs to the cultural heritage of the region, it is an example of human adaptation to the geographical environment, and an especially marvelous example of the convergence of continental climate and sedimentary or volcanic materials.

Among the different functions a cave serves, residence has become its most important role due to current improvements in its condition; from being considered a slum dwelling it has become an example of bioclimatic housing perfectly equipped for the requirements of the present, with a promising future. The demand for this sort of housing is growing both as a primary and a secondary home, and as such it currently plays also an economic role, linked to new economic activities.

Recovering the advantages of the cave as compared to other traditional constructions has resulted in an increase in value of the excavated spaces. This approach is doubly interesting, in that it encourages the restoration of architectural heritage while it helps people keep a record of the population, by stimulating activity, diversifying and expanding the limited opportunities the rural world has traditionally provided its inhabitants. 


\section{References}

Derruau, M. 1987. Human Geography. Barcelona, Vicens Vives. (in Spanish)

Diputación de Granada 2007. Caves in the Granada Province: Technical, urbanistics, legal and patrimonial aspects and prospects for local development of the Province. Alsul, Presentación. (in Spanish)

Jessen, O. I955 The trogloditic houses in the Mediterranean countries. Geographical Studies, pp. I37-I57. (in Spanish)

Lassaosa Castellanos, M.J. I989. Underground architecture: caves of Andalucia: inhabited sets, Junta de Andalucía. Dirección General de Arquitectura y Vivienda, Sevilla, Consejería de Obras Públicas y Transportes. (in Spanish)

Laureano, P. 2007. The Matera stones: a proposal from the ancient wisdom for the future in PARCHI. Rivista della Federazione Italiana Parchi e delle Riserve Naturali, N. 50. (In Italian)
Levi, C. 1947. Christ Stoppedat Eboli. Torino: Einuaudi Editore. (in Italian)

Maccarone, A. 2009. The underground landscape in Molise in comparison with other Mediterranean countries. Proposals for a classification and protection. PhD thesis. University of Molise (Italy). (in Spanish and Italian)

Urdiales Viedma, M.E. I987. Caves of Andalusia. Evolution, status and demographic analysis in the province of Granada. Consejería de Obras Públicas. Granada, Junta de Andalucía. (in Spanish)

Urdiales Viedma, M.E. 1989. Settlement and rural habitats in Spain in Bosque Maurel. Geografía de España 2, 476- 500. (in Spanish)

Urdiales Viedma, M.E. 2003. The cave-dwelling in Andalusia: from the slum housing to the future. Scripta Nova. Revista electrónica de Geografía y Ciencias Sociales 7, I46, (05I).http:// www.ub.edu/geocrit/sn/sn-I46(05I).htm (in Spanish) 